\title{
Applying a Numerical Model to Obtain the Temperature Distribution while Machining
}

\author{
N. Melzi*, M. Temmar and M. Ouali \\ Structural Mechanics Research Laboratory, Department of Mechanical Engineering, University Blida 1, Algeria \\ The turning process is one of the best used processes in the mechanical industry. Therefore, the choice of \\ the cutting parameters is very important in order to obtain a good machined surface quality. In this study, an \\ analytical model and a modeling of the contact of the cutting tool with the work piece are developed for an \\ orthogonal cutting process with a thermal analysis at the contact. The main aim is to predict the temperature \\ while machining. By using the high-speed machining, we notice that the greater part of the heat, generated by the \\ cutting process, is discharged into the cutting tool and the work piece. Indeed, when the cutting parameters, such \\ as the cutting speed or the feed increase, the temperature increases too.
}

DOI: 10.12693/APhysPolA.131.504

PACS/topics: 07.10.-h

\section{Introduction}

Today, the processes of machining by material removal occupy predominant place in the industry. These machining processes are commonly used in order to obtain final products.

The constant improvement of the machine tool performance, and especially of CNC machining, constantly revolutionizes in productivity, accuracy and cinematic possibilities for complex shapes.

In addition, the increased performances of cutting tools have made substantial productivity and quality gains, that helped to develop the performance of these processes.

In recent years, new standards of environmental protection have pushed users to reduce the lubrication during machining. Thus, such dry machining will induce efforts and higher temperatures. One solution to this situation is the introduction of the high-speed machining (HSM). Indeed, in the HSM, most of the heat generated by the cutting is discharged into the chip and the cutting tool; thereby alleviating the thermal stress on the work piece. However on the other hand HSM poses problems regarding the strength of the cutting tools.

By using the HSM, the milling machine uses a higher material rate at a high speed. However, the rational use of this technology is still heavily penalized by the lack of knowledge of the physical phenomena involved in metal cutting. Thus, it is important to use an effective modeling and optimization methods to understand the thermomechanical and chemical phenomena occurring at the contact of the cutting tool with the work piece. In order to study the cutting phenomena, three different approaches are used: (i) mechanistic approach, based on experimental measurements of references, (ii) analytical

*corresponding author; e-mail: melzinesrine@gmail.com approach, which seeks to describe the geometry and the thermo mechanical phenomena involved when cutting, (ii) approach by finite elements.

During our research, we have found that many scientists had worked on the prediction of the temperature while machining. Molinari et al. have developed an analytical model of orthogonal cutting, which then was extended by Moufki et al. [1, 2]. Their model permits to predict the efforts, the contact length of cutting toolchip, the pressure at the tool tip or the temperature distribution in the cutting tool-chip interface. Ashok et al. have developed response surface methodology and optimization of process parameter, performed by desirability approach. Basak at al. have studied the optimization of finishing of hard turning process for the machining. The aim is to choose the appropriate process parameters. Bapat et al. have developed a model to predict the temperature distribution during hard turning of AISI 52100 steel [3-5].

Others have shown experimentally that the average friction varies with such parameters as advance and speed. Moufki et al. have suggested a relationship, giving the coefficient of friction, according to the average temperature at the interface, which is itself a function of different parameters.

\section{Temperature distribution using $3 \mathrm{D}$ turning simulations (ANSYS)}

In the proposed experience, we have used a Heckert parallel turning machine (DZFG 200 with a power of $5.5 \mathrm{~kW}$ ). The cylindrical work piece material was made of XC 48 steel. Our work is based entirely on tests of a cutting tool and a work piece. The main aim is to predict the temperature while machining.

During the analysis, the cutting tool is considered sufficiently rigid with no deformation field.

The cutting tool is modeled by generating 68173 elements and 54769 nodes (Fig. 1). The thermo-mechanical coupling is introduced. 


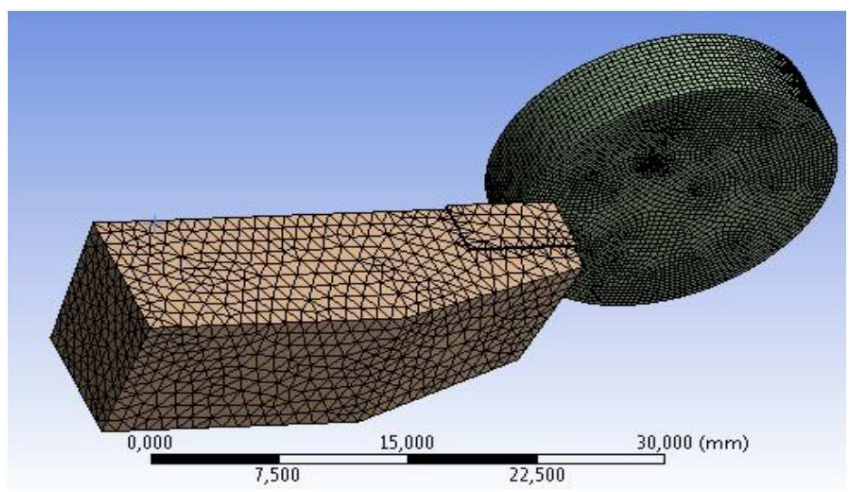

Fig. 1. Initial mesh of the cutting tool and the work piece.

The mesh distribution is uniform over the entire surface of the cutting tool. Mesh density was increased on the rake face of the cutting tool in order to obtain more precise parameters, like the temperature. Heat exchange is set over the volume control where the initial temperature is $22^{\circ} \mathrm{C}$.

\section{Modeling of the work piece}

To obtain satisfactory results while cutting the metal, the strain modeling of flows of the material of the work piece is very important. The part is modeled as a deformable body and the constitutive model of Johnson-Cook is used to describe the steel plastic behavior.

The criteria of flow and damage to the material, according to Johnson-Cook model are respectively given by the following equations:

$$
\begin{aligned}
& \sigma=\left(A+B\left(\bar{\varepsilon}^{\rho}\right)^{n}\right)\left(1+C \ln \frac{\dot{\bar{\varepsilon}}}{\dot{\bar{\varepsilon}}_{0}}\left[1-\left(\frac{T-T_{0}}{T_{\text {melt }}-T_{0}}\right)^{m}\right],\right. \\
& \varepsilon_{f}=\left(D_{1}+D_{2} \exp \left(D_{3}\right) \sigma^{*}\right)\left(1+D_{4} \ln \dot{\varepsilon}^{*}\right)\left(1+D_{5} T^{*}\right) .
\end{aligned}
$$

Johnson-Cook constants of the XC48 steel are shown in the Tables I and II.

TABLE I

Johnson-Cook constants of the plastic deformation of steel XC48.

\begin{tabular}{c|c|c|c|c|c}
\hline \hline$A[\mathrm{MPa}]$ & $B[\mathrm{MPa}]$ & $C$ & $n$ & $m$ & $T_{\mathrm{f}}[\mathrm{K}]$ \\
\hline 553.1 & 600.8 & 0.013 & 0.234 & 1 & 1460
\end{tabular}

TABLE II

Johnson-Cook constants (at the breaking of XC48 steel).

\begin{tabular}{c|c|c|c|c|c}
\hline \hline D1 & D2 & D3 & D4 & D5 & $\dot{\bar{\varepsilon}}_{0}\left[\mathrm{~s}^{-1}\right]$ \\
\hline 0.25 & 4.38 & 2.68 & 0.002 & 0.61 & 1
\end{tabular}

By applying the ANSYS program, we have obtained the following results (Figs. 2-5).

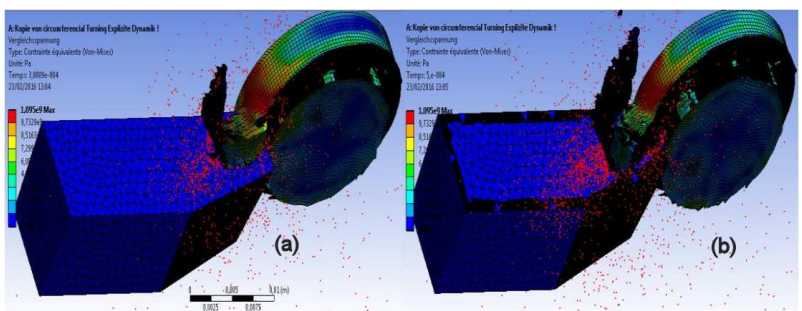

Fig. 2. (a) Stresses variation, (b) the morphology of the chip.
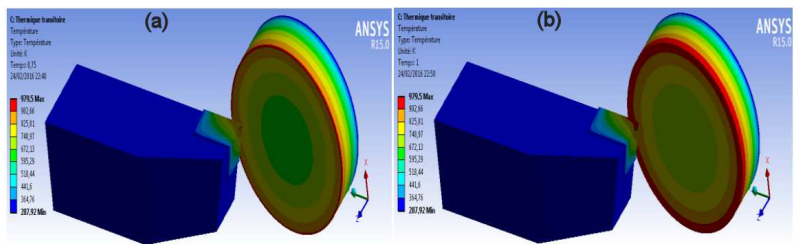

Fig. 3. Temperature distribution (a) $t=0.75 \mathrm{~s}$ (b) $t=1 \mathrm{~s}$.

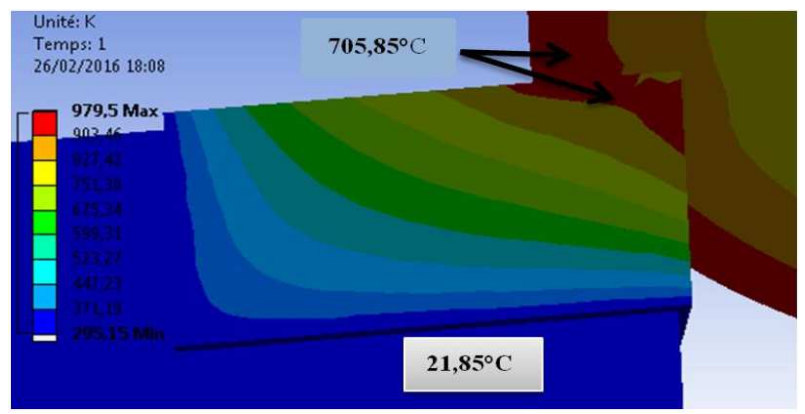

Fig. 4. Temperature distribution using a cutting speed of $200 \mathrm{~m} / \mathrm{min}$.

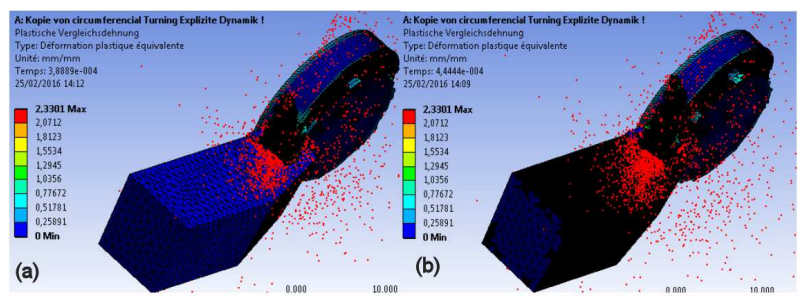

Fig. 5. The equivalent plastic strain simulation of Von Mises at the contact of the cutting tool and the chip.

\section{Conclusions}

In this study, a numerical model was developed to obtain temperature distribution during machining. Temperature distribution model was developed using ANSYS software. A series of simulations was carried out to obtain the value and region of maximum temperature at various cutting conditions. The simulated results of the temperature distribution have shown a good agreement with the results available in the literature, which shows that it is possible to apply our model. The developed model could be used to predict the temperature distribution and to choose correct process parameters during machining of XC48 steel. 


\section{Acknowledgments}

This research has been supported by The Structural Mechanics Laboratory of the University of Blida 1. Project Number: J 0300420120016.

\section{References}

[1] A. Molinari, D. Dudzinski, C.R. Academic. Sci. 315 399 (1992).

[2] A. Moufki, A. Molinariand, D. Dudzinski, J. Mechanic. Phys. Solids 46, 2103 (1998).
[3] K.S. Ashok, P.C. Mishra, Int. J. Industrial Engin. Comput. 5, 407 (2014).

[4] S. Basak, U.S. Dixit, J.P. Davim, Proc. Mechan. Engin. Part B: J. Engin. Manufact. 221, 987 (2007).

[5] P.S. Bapat, P.D. Dhikale, S.M. Shinde, A.P. Kulkarni, S.S. Chinchanikar, in: 4th Int. Conf. Materials Processing and Characterization, Materials Today: Proceedings 2, 2015, p. 1907. 